\title{
Use of Mesoporous Silica SBa-15 and SBa-16 in Association of Outer Membrane Vesicles - OMV from Neisseria meningitidis
}

Danilo A Alves, Ives B Mattos, Luciana M Hollanda and Marcelo Lancellotti*

LABIOTEC - Biotechnology Laboratory, Department of Biochemistry, Institute of Biology CP6109, University of Campinas - UNICAMP 13083-970, Campinas, SP, Brazil

\begin{abstract}
Outer membrane vesicles or OMV are nanoparticles released in culture medium during meningococcal growth resulting from evaginations of the outer cellular membrane and have been indicated as potential target for vaccine production. This study aimed to analyze the use of Neisseria meningitidis B2443, as vaccine using a semi-solid fermentation process based in ultrafiltration for the isolation these OMV and also verify the effect of the mesouporous silica (SBA-15 and SBA-16). The OMV preparation follow the method without the ultracentrifugation whose was subtituted by ultrafiltration method using a nitrocelulosis filtre showing a pore of $0.025 \mu \mathrm{m}$. For the detection of antibodies production were used the immunological method of ELISA, and serum bactericidal effect using sera from immunized mices with OMV and adjuvant inorganic nanoparticles. Also, the use of citotocity test were performed based in the neutral red uptake for safety of the associated vaccin use in NIH-3T3 cell line. It was compared to OMV production of strains of $N$. meningitidis strains B2443 and C2135. The results showed that different strains of $N$. meningitidis have OMVs kinetics of production of different time and quantity. The use of SBA-15 and SBA-16 as adujvant at $250 \mu \mathrm{g}$ for each mice was enough to induce an increase of vaccinal (for other serogroups) capacity same using a only OMV extracted from strains B2443. The study showed that the methodology used for the production of OMV is advantageous from the point of view of quantity and cost and use of this biologic nanoparticle. Both mesoporous silica SBa15 and SBa16 used in this work were capable to increase de recognition of antibody against different strains fo $N$. meningitidis showed using the OMV extracted from an only vaccinal strain.
\end{abstract}

Keywords: Neisseria meningitidis; Membrane vesicles

\section{Introduction}

The first vaccines target for meningococci were developed based in the pocapsular polyssacharide of the serogroups A, C, Y e W135 (Van der ley et al.). Also, the serogroup B polysaccharide is not immunologically capable enough to activate the complement system due the presence of $\alpha-2,8-\mathrm{N}$-acetil neuraminic acid. Thus, the new vaccines against the meningococci belonged to serogroup $B$ are actually based in proteins exposed in the outer membrane bacterial surface, as those presents in the outer membrane vesicles - the OMV [1-4]

For this reason all the vaccines disposable for the serogroup $\mathrm{B}$ immunization are based in OMVs, as the Cuban vaccine VAMENGOC-BC ${ }^{\circledR}$ extracted from Cu385/83 strain added of serogroup C polysaccharide (PSC) [5,6], the Norwegian Folkehelsa ${ }^{\circ}$, with OMV formuled from 44/76 strain [7-11] and the hexavalent Dutch vaccine Hexamen, composed of two different strains expressing three different subtypes of porin A [12].

Also, the characterization of OMV describe this biologic nanoparticles with a diameter 10 at $100 \mathrm{~nm}$ produced while the meninogo cocci cells are in growth process as resulting of evaginations from $N$. meningitidis outer membrane $[13,14]$. These vesicles show an immunogenic effect due their biochemical composition of polysaccharides, phospholipids, lipo oligosaccharides and principally, proteins [15-18].

Recently, Hollanda et al. (Hollanda, et al.) and Mattos had been described the influence of mesopororus silica in the transformation process in Neisseria meningitides [19]. These nanoparticles are implicated in the protection of foreign DNA responsible for transformation process and involved in the capsular switching process [20], an important virulence mechanism of immunological escape of human vaccinated host $[21,22]$.

For this reason the use of the new strategies with nanotechnology in the amplification of vaccinal response has been performed. In this work the first study of the associated action of mesoporous silica and outer membrane vesicles was effectuated aiming the verification of vaccinal amplification using just one vaccinal strain - B2443, for OMV extraction. Also were verified the use of new strategies of OMV production using the ultrafiltration process, whose facilitated the future process of scale-up vaccine production and its future use of this technology vaccine popularization.

\section{Materials and Methods}

\section{Bacterial strains and media}

The characteristics of the strains used in this study are described in Table 1 . They were grown at $37^{\circ} \mathrm{C}$ under $5 \%$ of $\mathrm{CO}_{2}$ on $\mathrm{GC}$ agar medium (Difco) containing the supplements described by Lancellotti et al. $[19,20]$. For the fermentation process in GC semi-solid medium a concentration of $1 \times 10^{5}$ colony-forming units - cfu of C2135 strain were inoculated in Roux flasks with surface of $500 \mathrm{~cm}^{2}$ using the bacterial suspension in phosphate buffer $\mathrm{pH}$ 7.2.

\section{Semi-solid fermentation process and OMV extraction}

The N. meningitidis $\mathrm{B} 2443, N$. meningitidis $\mathrm{C} 2135$ strains were

*Corresponding author: Marcelo Lancellotti, Department of Biochemistry, Institute of Biology CP6109, State University of Campinas - UNICAMP, 13083-970, Campinas, SP, Brazil, Tel: +55 19352161 50; Fax: +55 193521 6129; E-mail: mlancell@unicamp.br

Received May 18, 2013; Accepted July 27, 2013; Published July 31, 2013

Citation: Alves DA, Mattos IB, Hollanda LM, Lancellotti M (2013) Use of Mesoporous Silica SBa-15 and SBa-16 in Association of Outer Membrane Vesicles - OMV from Neisseria meningitidis. J Vaccines Vaccin 4: 196. doi: 10.4172/21577560.1000196

Copyright: $\odot 2013$ Alves DA, et al. This is an open-access article distributed under the terms of the Creative Commons Attribution License, which permits unrestricted use, distribution, and reproduction in any medium, provided the original author and source are credited. 
grown in GC media as described above. An initial inoculum of $1.10^{5}$ $\mathrm{cfu} / \mathrm{ml}$ of bacterial strains was performed in Roux flasks containing 100 $\mathrm{mL}$ of semi-solid GC medium (1.5\% of agar). After the times of $8,12,16$ and 24 hours the colonies grown in each Roux flasks were mechanically removed in $50 \mathrm{~mL}$ of PBS. This suspension was centrifuged at $4000 \mathrm{rpm}$ by 10 minutes and the whole supernatant was submitted to vacuum filtration using a nitrocellulose membrane with pore of $0.025 \mu \mathrm{m}$. The OMV remains retained in nitrocellulose membrane being released by washing with PBS. The OMV were then maintained at $-80^{\circ} \mathrm{C}$.

\section{OMV SBa-15 and SBa-16 Nanocharacterization}

The quantification of proteins were made following the Bradford protocole. For the Bradford assay (Bradford, 1976), we used the bovine serum albumin (BSA) to make the standard curve. To do so was used Concentrated Dye BioAgency ${ }^{\circ}$ (cod. 500-0006N) and the reading was performed at $595 \mathrm{~nm}$. The results were expressed as $\mu \mathrm{g}$ of protein per $\mathrm{ml}(\mu \mathrm{g} / \mathrm{ml})$. All results are the average of measurements performed in triplicate. The concentration of OMVs obtained by this process relies on its protein concentration, all the samples were diluted to reach the same concentration of protein as the less concentrated sample and the same volume of them were used for all the other assays. The kinetics was determined at each time comparing the C2135 and B2443 strain. The zeta potential of each nanoparticles were Particle size, polydispersion and zeta potential of the samples were analyzed using a Malvern Instruments Zetasizer Nano ZS operated at $25^{\circ} \mathrm{C}$ using triplicate readings and a 2 min equilibration time.

\section{Cell viability and in vitro cytotoxicity assay}

The test has been previously described by Borenfreund in 1985 (\& Shopsis Borenfreund, 1985). After incubation of NIH-3T3 cells with same volumes of OMVs for 3 hours the culture medium was removed and washed with phosphate buffered saline (PBS) $\mathrm{pH}$ 7.4. To each well was added $0.2 \mathrm{~mL}$ of RPMI 1640 medium containing $50 \mathrm{mg} / \mathrm{mL}$ of neutral red dye and the plate was incubated for $3 \mathrm{~h}$ at $37^{\circ} \mathrm{C}$ for uptake of the dye by the lysosomes of viable cells. After incubation, the medium containing the dye was removed and the wells were washed briefly with calcium-formalin solution for fixation. Immediately after, $0.2 \mathrm{ml}$ of ethanol-acetic acid was added to each well and the plate was kept for 15 minutes. The solubilized dye was quantified by spectrophotometer at $540 \mathrm{~nm}$.

\section{Animal immunization protocols}

The immunization protocol was approved by CEUA- UNICAMP, SP, Brazil, Protocol no 2529-1. For immunological tests were used the females of four weeks old of Swiss line $(n=5)$. The four mice groups $(n=5)$ were designed as: negative control non immunized, immunized with OMV (1ug), immunized with OMV (1 ug) + SBA-15 (250 ug), and immunized with OMV (1 ug) + SBA-16 (250 ug). The immunizations were performed by intraperithoneal way in two equal doses with an interval of one week [23].

\begin{tabular}{|c|c|c|}
\hline Strain & Characteristics & Origin \\
\hline C2135 & N. meningitidis serogroup C BioMerieux Vaccinal Strain & INCQS \\
\hline B2443 & N. meningitidis serogroup B:4,7:P1-15,19 & IAL \\
\hline B4 & N. meningitidis serogroup B4:P1-7,16 & IAL \\
\hline P2354 & N. meningitidis serogroup B: NT:P1.7-2,3 Cluster A4 & INCQS \\
\hline P2498 & N. meningitidis serogroup C: NT:P1.7-2,3 Cluster A4 & INCQS \\
\hline Y USA & N. meningitidis serogroup Y strain & IAL \\
\hline & Table 1: Bacterial Strains used in this work. \\
\hline
\end{tabular}

\section{Enzyme linked immune sorbent assay - ELISA}

The strains described on table 2 were grown in chocolate agar and a suspension of bacterial cells was made in phosphate buffer $\mathrm{pH} 7.4$ Those suspensions were inactivated at $56^{\circ} \mathrm{C}$ by 1 hour and distributed in aliquots of $100 \mu \mathrm{L}$ in 96 wells microplate. Plates were dried at $45^{\circ} \mathrm{C}$ by 18-24 hours for bacterial coating. The ELISA assay for antibodies detection follow using the mice sera obtained in the each experimental group, i.e., immunized with OMV $(1 \mu \mathrm{g})$, immunized with OMV (1 $\mu \mathrm{g})+$ SBA-15 $(250 \mu \mathrm{g})$, and immunized with OMV $(1 \mu \mathrm{g})+\mathrm{SBA}-16$ $(250 \mu \mathrm{g})$, as a first antibody and the Anti-mouse IgG (whole molecule) conjugated with goat peroxidase (Sigma Aldrich, Saint Louis, MO, USA) was used as second and staining antibody. The ELISA staining were performed with o-phenylenediamine - OPD and $\mathrm{H}_{2} \mathrm{O}_{2}$ use in $0,1 \mathrm{M}$ phosphate-citrate buffer $\mathrm{pH} 5.0$ (Sigma Aldrich, Saint Louis, MO, USA). The reaction has their absorbance measure at $490 \mathrm{~nm}$ and these results described in basorbance obtained for each mice sera dilution as described in figure 3.

\section{Serum bactericidal assay}

Bactericidal assays were performed by agar overlay method [24] with 2 -fold dilutions (initial dilution at $1 / 50$ ) of the mice sera in sterile microtitre plates using 25\% guinea-pig complement and a log-phase growth inoculum of about 200-400 CFU per well of strains described at table 1 . The grown on plates with brain heart infusion agar with $1 \%$ calf serum. The final dilution of the sera in the first well was 1:400, and bacteria were incubated at 30 minutes at $37^{\circ} \mathrm{C}$ before addition of the agar. Bactericidal titres were recorded as the highest reciprocal serum dilution that yielded $>50 \%$ killing of the target strain B2443. Results obtained from this analysis were described on Table 2.

\section{Statistical analysis}

The data from each assay were statistically analyzed using Tukey's

\begin{tabular}{|c|c|c|c|}
\hline \multirow{2}{*}{ Strain } & \multicolumn{3}{|c|}{ Sera Dilution } \\
\cline { 2 - 4 } & OMV w/o MS & OMV + SBa15 & OMV+SBa16 \\
\hline P2498 & ${ }^{*}(\mathrm{a})$ & $1: 50$ & $1: 100$ \\
\hline B2443 & $1: 100$ & $1: 100$ & $1: 400$ \\
\hline C2135 & ND & ND & ND \\
\hline B4 & ${ }^{*}(b)$ & ${ }^{*}(b)$ & ${ }^{*}(b)$ \\
\hline P2354 & $1: 100$ & $1: 100$ & $1: 400$ \\
\hline Y USA & $1: 50$ & $1: 50$ & $1: 100$ \\
\hline
\end{tabular}

*(a) is not showed a bactericidal effect

*(b) the strain B4 was sensible to rabbit complement and not showed grown in the test

Table 2: Bacteria strains and Serum Bactericidal activity of mice sera immunized with OMV from B2443.

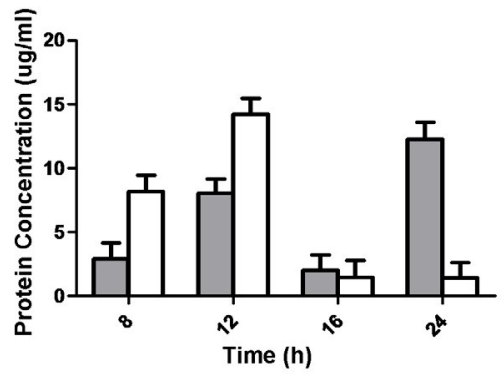

Figure 1: Kinetics of OMV Protein associated determination. Values expressed in mean \pm standard deviation. Strains C2135 (Gray) and B2443 (White). 
Citation: Alves DA, Mattos IB, Hollanda LM, Lancellotti M (2013) Use of Mesoporous Silica SBa-15 and SBa-16 in Association of Outer Membrane Vesicles - OMV from Neisseria meningitidis. J Vaccines Vaccin 4: 196. doi: 10.4172/2157-7560.1000196

test compared with a control sample and $\rho<0.05$ was considered significant. All experiments were performed in triplicate and the data shown in the graphs and in the table represent the means \pm standard errors.

\section{Results and Discussion}

The OMV's extraction was evaluated comparing the values obtained from protein detection in strains C2135 and B2443 of $N$. meningitidis (Figure 1). Also, the determination of different stages in which each extraction/strain took place, have shown the importance of the variation of the parameters such as strain and bacterial growth in the scale up process in OMV. The analysis of figure 1 showed that the C2135 strain had its optimal time for OMV productions at 24 hours, while the strains belonging to serogroup B - B2443 strain - showed its optimal time at 12 hours. The use of semi-solid fermentation process allows verifying the effect of the protein expressed in bacterial surface such as a piline [25]. Also, the use of a process dispensing detergent as desoxicolate salts showed an acquisition of an immunogenic OMV, capable to induce an immune response when used as vaccine.

Furthermore in the semi-solid fermentation method, based in bacterial recoated, there is no damage to OMV extraction leading to
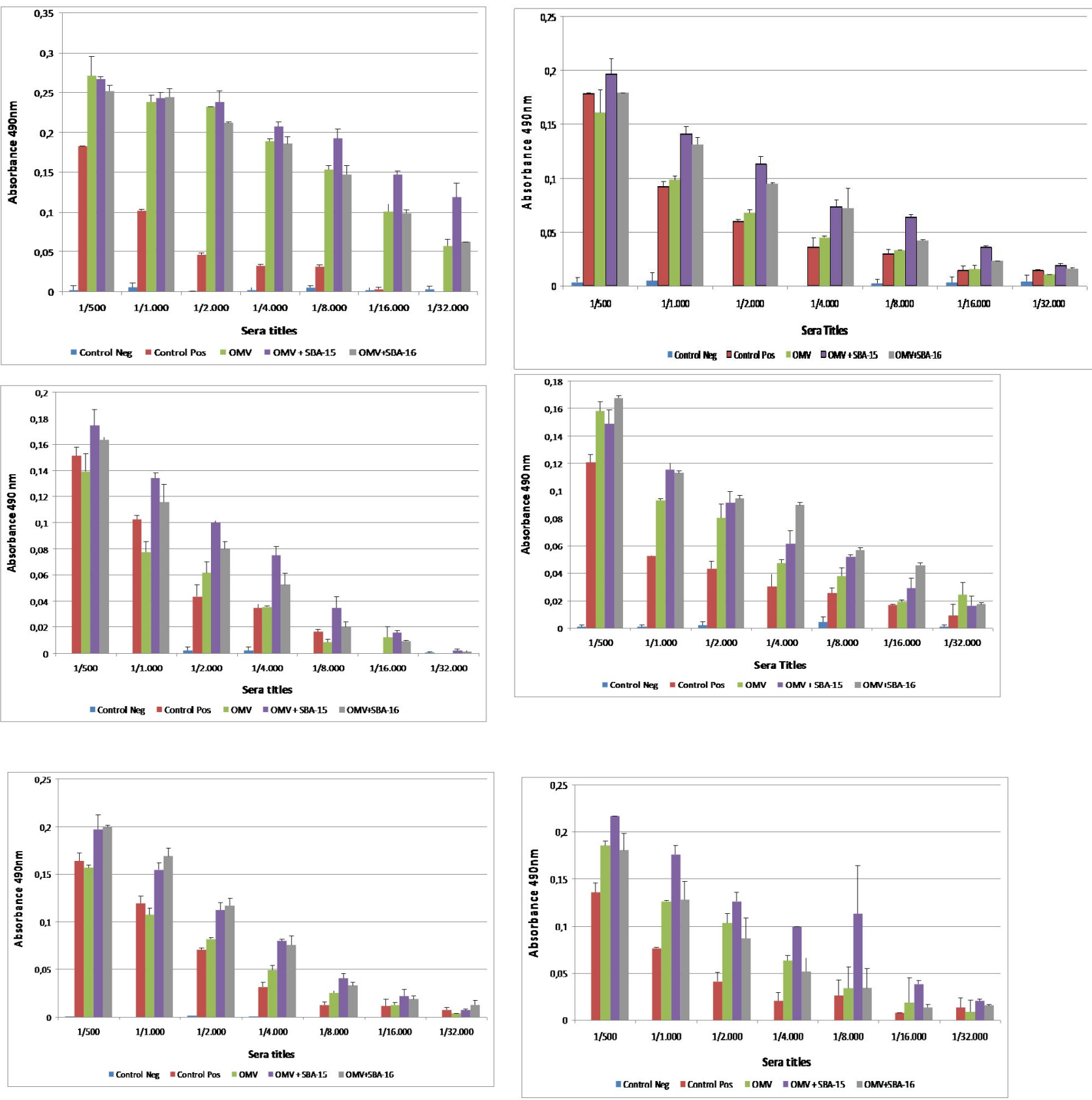

Figure 2: Analysis of the recognition of sera from mice immunized. In the positive control - was used a rabbit sera), OMV (serum from mice immunized with OMV from IAL 2443 strain), OMV + SBA-15 (mice vaccinated with association of SBA- 15 and OMV) and OMV + SBA-16 (serum from mice immunized with OMV associated with SBA-16). In the figure 2A was used as bacterial coating the vaccine strain B2443, in 2B coating of P2354 strain, 2C - B4 strain, 2D - P2498 strain, 2E- C2135 strain and 2F- YUSA strain. 
the conservation of antigenic structures existents in meningococcal surface, as for example, the pilin. These structures are easier produced in immobilized or semi-solid conditions on a scale-up process. The use of nitrocelulose membrane with a pore size of $25 \mathrm{~nm}$ allows an efficiency of OMV extraction letting the replacement of the detergents and ultracentrifugation.

In assays performed to verify the recognition of antibodies in mice immunized with OMV extracted from strain B2443, with SBA-15 and SBA-16 as adjuvant against different strains of meningococci. These analyses aimed to verify the increasing recognition of epitopes in other meningococci strains from various serogroups. In Figure 2 (coating with vaccinal strain) coating strains $\mathrm{P} 2354$ and $\mathrm{B} 4$, respectively, have demonstrated the presence of antibodies against the B4 and P2354 in immunized mice with OMV from B2443 strain.

When the immunization process was associated with nanoparticles SBA-15 and SBA-16 it was found a significant increase in the immune response from $1: 1,000$ to $1: 8,000$ dilutions (Table 4). Then, the association of SBA-15 showed a major effectiveness when compared with SBA-16. In Figure 2 where the strain P2354, that also belongs to serogroup B strain, similar at the vaccinal strain IAL 2443, was analyzed about the recognition of its epitopes when the mice were vaccinated with OMV associated with SBA-15 and SBA-16, an increase in immune response with a titers of mice sera between 1:500 to 1:16.000 was observed.

Probably, the association with SBA-15 was more effective when compared to SBA-16 in the strain B2443. This strain has its capsular polysaccharide classified in the serogroup B according Borrow et al. [26], due to the presence of acid molecule $\alpha-2,8-\mathrm{N}$-acetyl neuraminic. This compound is very similar to human sialic acid, which is present in the capsule serogroup B, therefore the existing vaccines are not as effective.

The analysis of bactericidal effect of sera confirm the hypothesis to adjuvant effect principally when observed the sera activity of sera from mice immunized with OMV (strains B2443) additioned with SBa15 (with titer of immune response in 1:50) and SBa16 (with titer in 1:400). The same strain P2498 did not showed a bactericidal effect with the sera from mice immunized just OMV, i.e., without mesoporous adjuvants. The P2498 strain belongs to C serogroup and show in its surface different antigenic constituents as could view in their genetic characterization described in the table 1.

Also analyzing the ELISA of serum from mice immunized with OMV N. meningitidis IAL 2443 against other bacterial coating such as N. meningitidis C2135, N. meningitidis $\mathrm{P} 2498$ and N. meningitidis $\mathrm{Y}$ USA, that belong to different serogroups of meningococcus, the results obtained indicate that the same recognition occurs using an OMV from IAL 2443 strain increasing the antibodies recognition against the serogroup C strains (P2498 and C3135) and serogroup Y USA strain. The animal sera vaccinated with the OMV preparations, the OMV combined with SBA-15 and the OMV combined to SBA-16 reached until high titers of dilution (1: 2000 to $1: 32,000)$. The data where the polydispersion and the zeta potential of each OMV were analyzed

\begin{tabular}{|c|c|c|}
\hline Strain & Zeta Potential $(\mathbf{m V})$ & Polydispersion (r.nm) \\
\hline P2498 & $-25,2+6,71$ & $57,93+22,20$ \\
\hline B2443 & $-21,7+8,50$ & $94,67+21,90$ \\
\hline C2135 & $-30,2+6,49$ & $172,4+103,8$ \\
\hline B4 & $-15,5+6,60$ & $84,91+15,09$ \\
\hline Y USA & $-16,4+7,90$ & $78,46+28,41$ \\
\hline
\end{tabular}

Table 3: OMV strains and polydispersion and zeta potential.
(Table 3) showed a charge characteristics of organic OMV with zeta potential and polydispersion. The inorganic nanoparticles SBa-15 and SBa16, previously published in Hollanda et al. (2011), with a probable interaction with the OMV considered as an organic and naturally produced nanostructure. These OMV were also characterized about their nanostructure considered negative in relationship with other macromolecules as proteins (zeta potencial with values between -15.5 at $-30.2 \mathrm{mV}$ and polydirpersion with values between 57.3 at $172.3 \mathrm{~nm}$ ). Thus, the adjuvant effect of mesoporous silica could also be studied in considering the molecular interactions of these nanostructures and the several compound that contained in biological and complex OMV. A statistic analysis is described in the table 4 showing the significant $\rho$ values for each dilution of the different immunizations used in this work.

Nevertheless, the adjuvant capacity of the same silica nanoparticles, in particular SBa-16 to support the recognition, showed higher absorbance values, leading to increased serum levels of recognition for this lineage. This recognition is clear and significant $(\mathrm{P}<0.05)$ for serum titers of $1: 4000$ and $1: 8000$.

In general, the use of nanoparticles of silica SBA-15 and SBA-16 as vaccine adjuvant in meningocci vaccines is an unprecedented fact in vaccine scientific literature. Increased rates of immune response and greater coverage of a vaccine directed against serogroup $B$ vaccine strain and also against other strains belonging to different serogroups of $N$. meningitidis were apparently achieved.

Such property may be due to a better presentation of vaccine epitopes with an effective activation of antigen-presenting cells by the mesoporous silica. Authors show that mesoporous silica is an important immune activator [26,27], with increase of immune response and consequent more effectively exposing other epitopes present in the mixture administrated.

In addition, new nanostructures such as carbon nanotubes, graphene and fullerenes may be targeted in future researches of this group, as well as new vaccines based in polyepitopics antigens, as complexes as OMV's or even isolated bacterial proteins are targets of recent studies in Vaccine Technology and Nanotechnology.

In conclusion, the use of mesoporous silica SBa-15 a tubular mesoporous silica and a spherical mesopourous silica $\mathrm{SBa}-16$ as vaccine

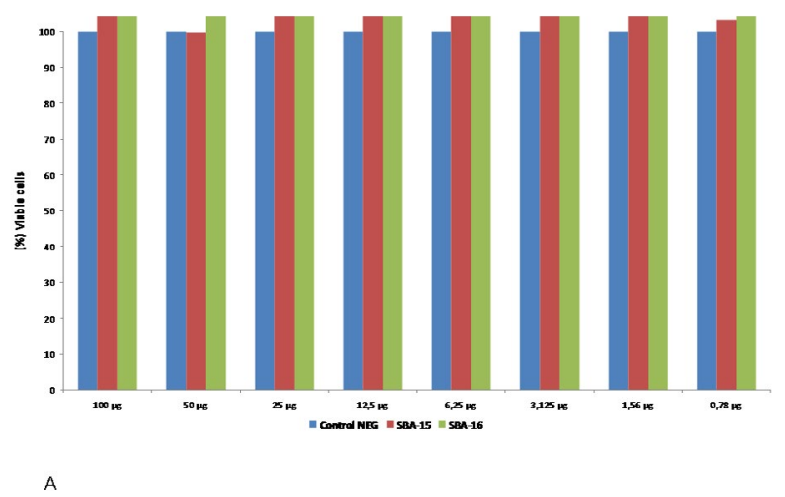

Figure 3: Cellular viability of NIH-3T3 of mesoporous silica and OMV. In (a) it view the OMV, SBa-15 and SBa-16 in several concentration in neutral red uptake assay for cellular viability verification. In (b) it observed the comparation of OMV and mesoporous silica association at different concentrations. All the neutral red assay non show a cytotoxicity effect in NIH-3T3 cells line. 
Citation: Alves DA, Mattos IB, Hollanda LM, Lancellotti M (2013) Use of Mesoporous Silica SBa-15 and SBa-16 in Association of Outer Membrane Vesicles - OMV from Neisseria meningitidis. J Vaccines Vaccin 4: 196. doi: 10.4172/2157-7560.1000196

Page 5 of 6

\begin{tabular}{|c|c|c|}
\hline Coating B2443 & & \\
\hline Titer & SBA-15 & SBA-16 \\
\hline $1: 500$ & $P=0,2310$, not significant & $P=0,3186$, not significant \\
\hline $1: 1.000$ & $P=0,2063$, not significant & $P=0,2524$, not significant \\
\hline $1: 2.000$ & $P=0,1494$, not significant & $P=0,5487$, not significant \\
\hline $1: 4.000$ & $P=0,0028$, very significant & $P=0,3148$, not significant \\
\hline $1: 8.000$ & $P=0,0018$, very significant & $P=0,1698$, not significant \\
\hline 1:16.000 & $P=0,0005$, extremely significant & $P=0,3667$, not significant \\
\hline $1: 32.000$ & $P=0,0003$, extremely significant & $P=0,2221$, not significant \\
\hline \multicolumn{3}{|l|}{ Coating B4 } \\
\hline Titer & SBA-15 & SBA-16 \\
\hline $1: 500$ & $P=0,0006$, extremely significant & $P=0,0005$ extremely significant \\
\hline $1: 1.000$ & $P \leq 0,0001$, extremely significant & $P=0,0003$ extremely significant \\
\hline $1: 2.000$ & $P=0,0002$, extremely significant & $P=0,0084$, very significant \\
\hline $1: 4.000$ & $P=0,0001$, extremely significant & $P=0,0027$, very significant \\
\hline $1: 8.000$ & $P=0,0004$, extremely significant & $P=0,0069$, very significant \\
\hline 1:16.000 & $P=0,1829$, not significant & $P=0,2112$, not significant \\
\hline $1: 32.000$ & $P=0,0411$, significant & $P=0,1691$, not significant \\
\hline \multicolumn{3}{|l|}{ Coating P2354 } \\
\hline Titer & SBA-15 & SBA-16 \\
\hline $1: 500$ & $P=0,0040$, very significant & $P=0,0043$, very significant \\
\hline $1: 1.000$ & $P \leq 0,0001$, extremely significant & $P=0,0009$, extremely significant \\
\hline $1: 2.000$ & $P \leq 0,0001$, extremely significant & $P \leq 0,0001$, extremely significant \\
\hline $1: 4.000$ & $P=0,0004$, extremely significant & $P=0,0008$, extremely significant \\
\hline $1: 8.000$ & $P \leq 0,0001$, extremely significant & $P \leq 0,0001$, extremely significant \\
\hline 1:16.000 & $P=0,0003$, extremely significant & $P=0,0064$, very significant \\
\hline $1: 32.000$ & $P=0,0004$, extremely significant & $P=0,0005$ extremely significant \\
\hline \multicolumn{3}{|l|}{ Coating C2135 } \\
\hline Titer & SBA-15 & SBA-16 \\
\hline $1: 500$ & $P=0,0464$, significant & $P=0,0186$, significant \\
\hline $1: 1.000$ & $P=0,0008$, extremely significant & $P \leq 0,0001$, extremely significant \\
\hline $1: 2.000$ & $P=0,0579$, not significant & $P=0,0129$, significant \\
\hline $1: 4.000$ & $P=0,0062$, very significant & $P \leq 0,0001$, extremely significant \\
\hline $1: 8.000$ & $P=0,0071$, very significant & $P=0,0033$, very significant \\
\hline 1:16.000 & $P=0,0151$, significant & $P \leq 0,0001$, extremely significant \\
\hline $1: 32.000$ & $P=0,2335$, not significant & $P=0,0635$, not significant \\
\hline \multicolumn{3}{|l|}{ Coating P2498 } \\
\hline Titer & SBA-15 & SBA-16 \\
\hline $1: 500$ & $P=0,0060$, very significant & $P \leq 0,0001$, extremely significant \\
\hline $1: 1.000$ & $P=0,0004$, extremely significant & $P=0,0002$, extremely significant \\
\hline $1: 2.000$ & $P=0,0013$, very significant & $P=0,0004$, extremely significant \\
\hline $1: 4.000$ & $P=0,0003$, extremely significant & $P=0,0063$, very significant \\
\hline $1: 8.000$ & $P=0,0046$, very significant & $P=0,0129$, significant \\
\hline 1:16.000 & $P=0,0449$, significant & $P=0,0167$, significant \\
\hline $1: 32.000$ & $P=0,0108$, significant & $P=0,0205$, significant \\
\hline \multicolumn{3}{|l|}{ Coating YUSA } \\
\hline Titer & SBA-15 & SBA-16 \\
\hline $1: 500$ & $P \leq 0,0001$, extremely significant & $P=0,0851$, not significant \\
\hline $1: 1.000$ & $P=0,0002$, extremely significant & $P=0,0831$, not significant \\
\hline $1: 2.000$ & $P=0,0159$, significant & $P=0,1733$, not significant \\
\hline $1: 4.000$ & $P \leq 0,0001$, extremely significant & $P=0,1084$, not significant \\
\hline $1: 8.000$ & $P \leq 0,0001$, extremely significant & $P=0,0011$, very significant \\
\hline 1:16.000 & $P \leq 0,0001$, extremely significant & $P=0,0007$, very significant \\
\hline $1: 32.000$ & $P \leq 0,0001$, extremely significant & $P=0,5000$, not significant \\
\hline
\end{tabular}

Table 4: Statistic anlalysis of ELISA test using the Tukey's test one way comparing the absorbance of sera obtained from mice immunized with OMV and ajuvant OMV + SBa-15 and OMV + SBa16.

adjuvants with OMV utilization is an important prophylactic measures against the human meningitis caused by meningococci.

\section{Acknowledgement}

This study has been financially supported by CAPES, FAPESP and Dr.
Edésia MB Sousa for gift the mesoporous silica for this work. These supports helped us to reagent supply and equipments for all this research development. FAPESP (number 2011/14079-2 and 2012/15043-6), funding the Laboratory of Biotechnology (Coordinated by M.L.). CAPES funding with the personal fellowships for students: IBM. Thanks for the English revision made by Ana Carolina Afonso. 
Citation: Alves DA, Mattos IB, Hollanda LM, Lancellotti M (2013) Use of Mesoporous Silica SBa-15 and SBa-16 in Association of Outer Membrane Vesicles - OMV from Neisseria meningitidis. J Vaccines Vaccin 4: 196. doi: 10.4172/2157-7560.1000196

\section{References}

1. Frasch CE (1990) Production and control of Neisseria meningitidis vaccines. Adv Biotechnol Processes 13: 123-145.

2. Frasch CE, Sacchi CT, Brandiolone MC, Vieiera VS, Leite LC (1991) Development of a second generation group B meningococcal vaccine. NIPH Ann 14: 225-230

3. Comanducci M, Bambini S, Brunelli B, Adu-Bobie J, Aricò B, et al. (2002) NadA a novel vaccine candidate of Neisseria meningitidis. J Exp Med 195: 1445-1454.

4. Borrow R, Balmer P, Miller E (2005) Meningococcal surrogates of protectionserum bactericidal antibody activity. Vaccine 23: 2222-2227.

5. Milagres LG, Ramos SR, Sacchi CT, Melles CE, Vieira VS, et al. (1994) Immune response of Brazilian children to a Neisseria meningitidis serogroup B outer membrane protein vaccine: comparison with efficacy. Infect Immun 62 : 4419-4424.

6. Milagres LG, Gorla MC, Sacchi CT, Rodrigues MM (1998) Specificity of bactericidal antibody response to serogroup B meningococcal strains in Brazilian children after immunization with an outer membrane vaccine. Infect Immun 66: 4755-4761.

7. Frederiksen W (1993) Ecology and significance of Pasteurellaceae in man--an update. Zentralbl Bakteriol 279: 27-34.

8. Zollinger WD, Moran EE, Devi SJ, Frasch CE (1997) Bactericidal antibody responses of juvenile rhesus monkeys immunized with group B Neisseria meningitidis capsular polysaccharide-protein conjugate vaccines. Infect Immun 65: 1053-1060.

9. Morley SL, Pollard AJ (2001) Vaccine prevention of meningococcal disease coming soon? Vaccine 20: 666-687.

10. Jódar L, Feavers IM, Salisbury D, Granoff DM (2002) Development of vaccines against meningococcal disease. Lancet 359: 1499-1508.

11. Pollard AJ, Moxon ER (2002) The meningococcus tamed? Arch Dis Child 87 13-17.

12. Claassen I, Meylis J, van der Ley P, Peeters C, Brons H, et al. (1996) Production, characterization and control of a Neisseria meningitidis hexavalent class 1 outer membrane protein containing vesicle vaccine. Vaccine 14: 1001-1008.

13. Devoe IW, Gilchrist JE (1973) Release of endotoxin in the form of cell wall blebs during in vitro growth of Neisseria meningitidis. J Exp Med 138: 1156-1167.

14. Poolman JT, Kriz-Kuzemenska P, Ashton F, Bibb W, Dankert J, et al. (1995) Serotypes and subtypes of Neisseria meningitidis: results of an international study comparing sensitivities and specificities of monoclonal antibodies. Clin Diagn Lab Immunol 2: 69-72.

15. Gotschlich EC (1975) Development of polysaccharide vaccines for the prevention of meningococcal diseases. Monogr Allergy 9: 245-258.
16. Johnston KH (1980) Antigenic diversity of the serotype antigen complex of Neisseria gonorrhoeae: analysis by an indirect enzyme-linked immunoassay. Infect Immun 28: 101-110.

17. Andersen SR, Bjune G, Høiby EA, Michaelsen TE, Aase A, et al. (1997) Outer membrane vesicle vaccines made from short-chain lipopolysaccharide mutants of serogroup B Neisseria meningitidis: effect of the carbohydrate chain length on the immune response. Vaccine 15: 1225-1234.

18. Findlow J, Taylor S, Aase A, Horton R, Heyderman R, et al. (2006) Comparison and correlation of Neisseria meningitidis serogroup B immunologic assay results and human antibody responses following three doses of the Norwegian meningococcal outer membrane vesicle vaccine MenBvac. Infect Immun 74: 4557-4565.

19. Hollanda LM, Cury GC, Pereira RF, Ferreira GA, Sousa A, et al. (2011) Effect of mesoporous silica under Neisseria meningitidis transformation process: environmental effects under meningococci transformation. J Nanobiotechnology 9: 28

20. Lancellotti M, Guiyoule A, Ruckly C, Hong E, Alonso JM, et al. (2006) Conserved virulence of $\mathrm{C}$ to $\mathrm{B}$ capsule switched Neisseria meningitidis clinical isolates belonging to ET-37/ST-11 clonal complex. Microbes Infect 8: 191-196.

21. Mattos IB, Alves DA, Hollanda LM, Ceragiogli HJ, Baranauskas V, et al. (2011) Effects of multi-walled carbon nanotubes (MWCNT) under Neisseria meningitidis transformation process. J Nanobiotechnology 9: 53.

22. Ala'Aldeen DA, Neal KR, Ait-Tahar K, Nguyen-Van-Tam JS, English A, et al (2000) Dynamics of meningococcal long-term carriage among university students and their implications for mass vaccination. J Clin Microbiol 38: 2311-2316.

23. Zarantonelli ML, Antignac A, Lancellotti M, Guiyoule A, Alonso JM, et al. (2006) Immunogenicity of meningococcal PBP2 during natural infection and protective activity of anti-PBP2 antibodies against meningococcal bacteraemia in mice. $J$ Antimicrob Chemother 57: 924-930.

24. Tsolakos N, Lie K, Bolstad K, Maslen S, Kristiansen PA, et al. Characterization of meningococcal serogroup $B$ outer membrane vesicle vaccines from strain 44/76 after growth in different media. Vaccine 28: 3211-3218.

25. Taha MK, Morand PC, Pereira Y, Eugène E, Giorgini D, et al. (1998) Pilusmediated adhesion of Neisseria meningitidis: the essential role of cell contactdependent transcriptional upregulation of the PilC1 protein. Mol Microbiol 28 : 1153-1163.

26. Carvalho LV, Ruiz Rde C, Scaramuzzi K, Marengo EB, Matos JR, et al. (2010) Immunological parameters related to the adjuvant effect of the ordered mesoporous silica SBA-15. Vaccine 28: 7829-7836.

27. Vallhov H, Kupferschmidt N, Gabrielsson S, Paulie S, Strømme M, et al. (2012) Adjuvant properties of mesoporous silica particles tune the development of effector T cells. Small 8: 2116-2124. 